\title{
Quality control of fibers end-milled from bamboo pipe using spiral tool path
}

\author{
K. Ogawa ${ }^{1}$, E. Aoyama $^{2}$, T. Hirogaki ${ }^{2}$, Y. Tomioka ${ }^{2}$ \\ \& H. Nakagawa ${ }^{1}$ \\ ${ }^{1}$ Department of Mechanical Systems Engineering, \\ The University of Shiga Prefecture, Japan \\ ${ }^{2}$ Department of Mechanical Engineering, Doshisha University, Japan
}

\begin{abstract}
The utilization of unused forest products is beneficial, and therefore the application of natural fibers to FRP products has been proposed. Bamboo fibers have attracted particular attention because bamboo has the fastest growth rate among various types of renewable natural fibers. Moreover, bamboo fibers have high specific strength and stiffness appropriate for structural materials. In the present study, we explain a new method designed to obtain high-quality bamboo fibers by effectively end-milling them with a machining center (MC) using numerical control (NC) and an automatic tool changer (ATC), which enables the manufacture of a wide variety of products. NC programs encoding a spiral tool path were used for the bamboo pipe in order to obtain bamboo fibers effectively. The fiber length and diameter were evaluated at various feed rates, cutting speeds, and depths of cut in the fiber direction. Microscopic observation showed that the length of the fibers obtained can be controlled by selecting the depth of cut along the bamboo fiber direction and the diameter can be controlled by adjusting the feed of the end-mill center, which is determined by spindle speed and feed speed of end-mill under a constant end-mill diameter. Thus the desired fiber shape can be controlled with consistently high accuracy using end-milling by adjusting the cutting conditions. Moreover, using spiral tool path end-milling with a straight cutting edge tool can efficiently acquire high quality straight bamboo fibers with no thermal damage.
\end{abstract}

Keywords: bamboo fiber, end-mill, machining center, spiral tool path. 


\section{Introduction}

Recently, industrial products made of fiber reinforced plastic (FRP) such as glass fiber-reinforced plastic (GFRP), are being utilized extensively because they have high specific tensile strength (that of GFRP is as high as steel) but are significantly lighter. The use of such materials may have a negative environmental impact because of problems associated with their disposal or destruction. Conversely, the utilization of unused forest products is beneficial to the environment, and therefore a method of acquiring and applying natural fibers to FRP products has been proposed [1-7]. Bamboo fibers, in particular, have attracted attention because bamboo has the fastest growth rate among the various types of renewable natural fibers, and is grown throughout Japan. Moreover, bamboo fibers have high specific strength and stiffness as appropriate for structural materials $[8,9]$. Bamboo fibers have been obtained from the wood-like plant through various methods, such as crushing or heat steaming the bamboo stems. Using these methods, however, it is difficult to control the diameter, length and other dimensions, as well as to obtain large quantities of a consistent, uniform shape as necessary for high-quality fiber components in industrial materials [10]. This paper attempts to obtain high quality bamboo fibers by endmilling with a machining center (MC) as an alternative to previous conventional methods. The MC makes it possible to manufacture many kinds of products and the proposed method boasts some advantages over conventional methods. The shape of the bamboo fibers can be controlled because all the machining center processes are controlled by digital program. Moreover, the spiral tool path should produce uniform bamboo fibers and allow accurate control of the shape of fibers by variation of the cutting conditions.

\section{Experimental method}

\subsection{Material}

Naturally growing Mousouchiku bamboo was used as the base material. The bamboo was cut using a metal saw into $100 \mathrm{~mm}$-long bamboo pipes in order to remove the bamboo joints. The bamboo pipes were then set on the table in an $\mathrm{MC}$ and end-milled. The waste bamboo obtained was used as the bamboo fibers used in the experiments.

\subsection{Machining equipment and conditions}

A ROBODRILL (Type: T14iDs, FANUC Co., Ltd.) was used as the MC for milling. The end-mill tool used in the experiments was a square type with two straight cutting edges, and made of high-speed steel without coating films on the tool surface. The end-mill diameter was $6 \mathrm{~mm}$. Table 1 shows the machining conditions. The tool followed a spiral path from the perimeter to the center with a cutting depth of $50 \mu \mathrm{m}$ per one cycle in the radius direction of bamboo, as shown in Fig. 1. 
Table 1: $\quad$ Machining conditions.

\begin{tabular}{l|c}
\hline \hline Spindle speed $S(\mathrm{rpm})$ & $2500,5000,10000$, \\
& 15000,20000 \\
\hline Feed speed $F(\mathrm{~mm} / \mathrm{min})$ & $250,500,750$, \\
& 1000,2000 \\
\hline Depth of cut in radius direction $R_{v}(\mathrm{~mm})$ & 0.05 \\
\hline Depth of cut in bamboo fiber direction $A_{d}(\mathrm{~mm})$ & $2.5,5,8,10$ \\
\hline End-mill radius $r(\mathrm{~mm})$ & 3 \\
\hline Number of end-mill cutting edge $Z$ & 2 \\
\hline
\end{tabular}

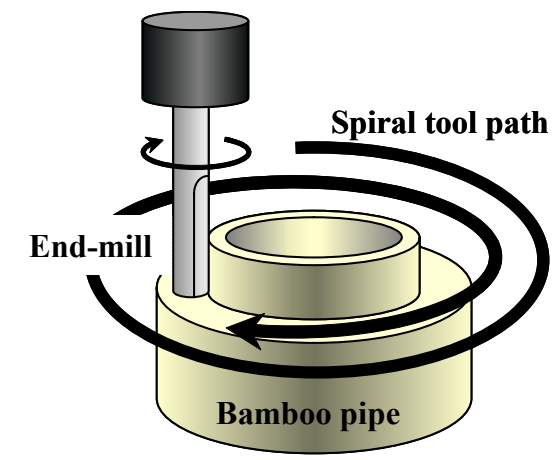

Figure 1: $\quad$ Spiral tool path.

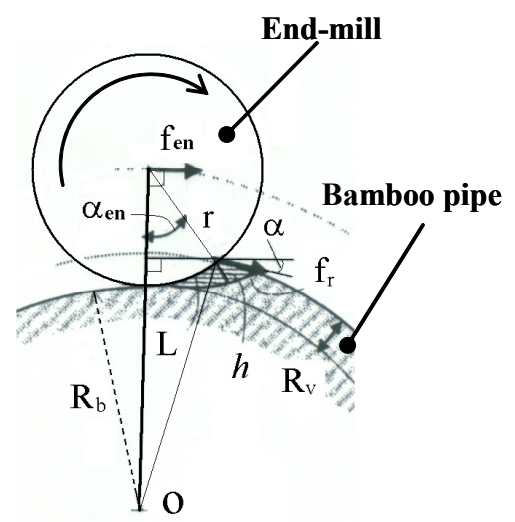

Figure 2: Convex contour cutting.

\subsection{Theoretical cutting configuration}

Figure 2 shows a diagram of the geometrical configuration. Here, $f_{r}$ is the feed of the cutting edge (mm/tooth), $f_{\text {en }}$ is the feed of the end-mill center ( $\mathrm{mm} /$ tooth), $r$ is the end-mill radius $(\mathrm{mm}), R_{v}$ is the depth of cut in the radius direction per cycle 
(mm), $R_{b}$ is the bamboo radius after cutting ( $\left.\mathrm{mm}\right), \alpha$ is the angle between the $f_{r}$ and $f_{e n}$ directions (rad), and $\alpha_{e n}$ is the cutting engagement angle (rad). The tool path approaches to a circumference path because the depth of cut in the bamboo pipe radius direction is very small comparing with the end-mill radius and the bamboo pipe radius.

The cutting arc length $L$ and the maximum thickness $h$ are obtained respectively based on the geometrical configuration shown in Fig. 2.

$$
\begin{gathered}
L=r \cdot \sin \alpha_{e n} \\
h=f_{r} \cdot \sin \left(\alpha_{e n}+\alpha\right)
\end{gathered}
$$

Here, the depth of cut in the radius direction per cycle $R_{v}$ is very small compared with the end-mill radius $r$ and the bamboo pipe radius $R_{b}$. As a result, the cutting engagement angle $\alpha_{e n}$ is extremely small, so as to be nearly zero. Therefore, eqn (3) can be obtained from eqn (1) using the approximation $\sin \alpha_{e n} \fallingdotseq \alpha_{e n}$.

$$
L=r \cdot \alpha_{e n}
$$

Eqns (4) and (5) can be obtained by the geometrical relation of the triangle that consists of the bamboo pipe center point, the end-mill center point, and the sharp end of the end-mill cutting edge, as shown in Fig. 2.

$$
\begin{gathered}
r \cdot \sin \alpha_{e n}=\left(R_{b}+R_{v}\right) \cdot \sin \alpha \\
r \cdot \cos \alpha_{e n}+\left(R_{b}+R_{v}\right) \cdot \cos \alpha=R_{b}+r
\end{gathered}
$$

Eqn (6) is obtained from the relation that the ratio of the feed of the cutting edge $f_{r}$ and the feed of the end-mill center $f_{e n}$ is equivalent to the ratio of the distance from the spiral path center to the end-mill center point and to the sharp end of the end-mill cutting edge.

$$
\frac{f_{e n}}{f_{r}}=\frac{R_{b}+r}{R_{b}+R_{v}}
$$

Here, the eqn (7) is conducted by eqns (2), (4), (5), and (6).

$$
h=f_{e n} \cdot \sin \alpha_{e n}
$$

Therefore, eqns (8) and (9) can be obtained by replacing the parameters utilized in this study shown in Table 1 into eqns (3) and (7).

$$
\begin{gathered}
L=r \cdot \arccos \frac{r-R_{v}}{r} \\
h=\frac{F}{S \cdot Z} \sqrt{\frac{R_{v}}{r}\left(2-\frac{R_{v}}{r}\right)}
\end{gathered}
$$

\subsection{Evaluation method of bamboo fiber quality}

The length and diameter of one hundred randomly selected bamboo fibers were measured using an optical microscope. Then aspect ratio, calculated by dividing the fiber length by the diameter, was then calculated to give an indication of the length and narrowness of the obtained fibers. Here, a theoretical fiber diameter $D_{t h}$ seems $(L+h) / 2$ in this method. 


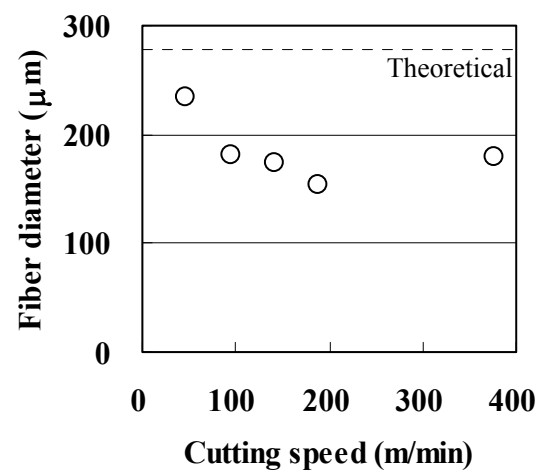

(a) Fiber diameter

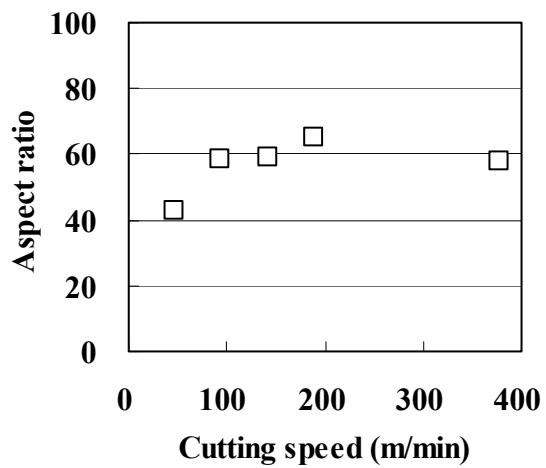

(c) Aspect ratio

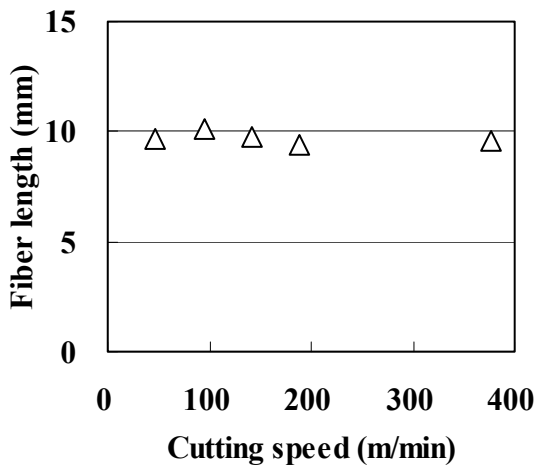

(b) Fiber length

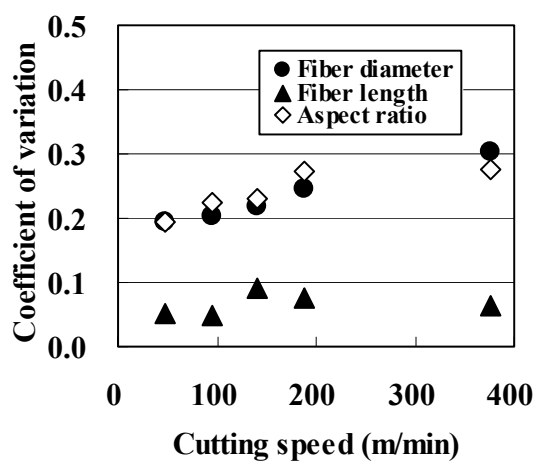

(d) Coefficient of variation

Figure 3: Change of bamboo fiber shape with cutting speed ( $f_{e n}=0.05 \mathrm{~mm} /$ tooth, $A_{d}=10 \mathrm{~mm}$ ).

\section{Results and discussion}

\subsection{Influence of cutting speed on acquired bamboo fiber quality}

Figures 3(a), 3(b) and 3(c) show the changes in fiber shape with cutting speed under a constant feed of the end-mill center of $0.05 \mathrm{~mm} /$ tooth and a cut of depth in the fiber direction of $10 \mathrm{~mm}$. Figure 3(d) shows the coefficient of variation of the acquired bamboo fiber shapes at various cutting speeds. The coefficient of variation is calculated by dividing the standard deviation by the mean value.

Here, the cutting speed $V(\mathrm{~m} / \mathrm{min})$ and the feed of end-mill center $f_{\text {en }}$ can be calculated by eqns (10) and (11), respectively.

$$
\begin{aligned}
& V=2 \pi r \cdot S \\
& f_{\text {en }}=\frac{F}{S \cdot Z}
\end{aligned}
$$


Therefore, the feed speed $F$ was adjusted for various spindle speed in order to match the constant feed of the end-mill center. Under these conditions, the endmilled sections of the fibers are theoretically uniform. That is, $L$ and $h$ are 548.5 $\mu \mathrm{m}$ and $9.1 \mu \mathrm{m}$, respectively, from eqns (8) and (9). As a result, the theoretical diameter is about $276.5 \mu \mathrm{m}$.

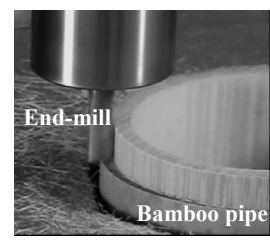

(a) Optical view

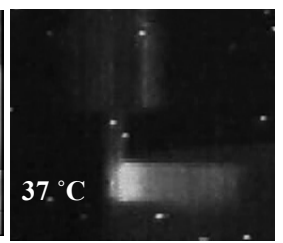

(b) $V=94 \mathrm{~m} / \mathrm{min}$ $(S=5000 \mathrm{rpm})$

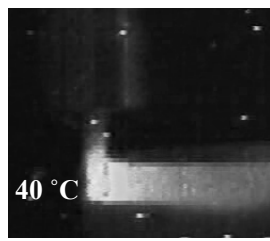

(c) $V=188 \mathrm{~m} / \mathrm{min}$ $(S=10000 \mathrm{rpm})$

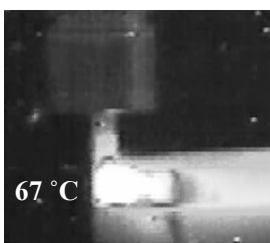

(d) $V=377 \mathrm{~m} / \mathrm{min}$ $(S=20000 \mathrm{rpm})$

Figure 4: Cutting temperature as monitored by thermography $\left(f_{e n}=0.05 \mathrm{~mm} /\right.$ tooth, $\left.A_{d}=10 \mathrm{~mm}\right)$.

The results verify that the diameter of the end-milled bamboo fiber decreases with cutting speed until about $200 \mathrm{~m} / \mathrm{min}$ though obtained fiber diameter has good agreement with theoretical one under low cutting speed. However, above this speed, the fiber diameter remains almost constant. On the other hand, the fiber length is almost constant, at $10 \mathrm{~mm}$, for any cutting speed. As a result, the aspect ratio increases with cutting speed until about $200 \mathrm{~m} / \mathrm{min}$ and then plateaus at a fiber diameter of about $150 \mu \mathrm{m}$ at the cutting speeds above $200 \mathrm{~m} / \mathrm{min}$. Higher cutting speed with greater feed speed improves the machining throughput. However, the coefficient of variation for the fiber diameter, fiber length and aspect ratio show a similar tendency of increasing with cutting speed. Therefore, a cutting speed of about $200 \mathrm{~m} / \mathrm{min}$ is suitable in order to obtain high efficiency machining and maintain low variation. It seems that the bamboo fiber diameter is controlled by cutting speed under about $200 \mathrm{~m} / \mathrm{min}$.

On the other hand, the increased cutting heat generated may damage the bamboo fiber in end-milling; the cutting temperature increases with cutting speed. The cutting temperature in steel rises to $800{ }^{\circ} \mathrm{C}$ or higher. The melting points of bamboo pipe components of cellulose, hemi cellulose, and lignin are about 240,180 , and $420{ }^{\circ} \mathrm{C}$, respectively. The temperature in bamboo cutting was monitored by thermography as a non-contact method. It can be seen that the temperature in bamboo cutting also increases with cutting speed as shown in Fig. 4. However, up to a cutting speed of $200 \mathrm{~m} / \mathrm{min}$ the temperature grows to no more than about $70{ }^{\circ} \mathrm{C}$. It can be concluded that under these conditions bamboo fibers end-milled from bamboo will sustain no thermal damage.

\subsection{Influence of cut of axial depth along the fiber direction on acquired bamboo fiber quality}

Figures 5 shows the microscopic images of end-milled bamboo fibers under various axial cut depths. It can be seen that uniform, straight fibers with no 
thermal damage are acquired. However, fibers end-milled appear as powders with smaller axial cut depth.

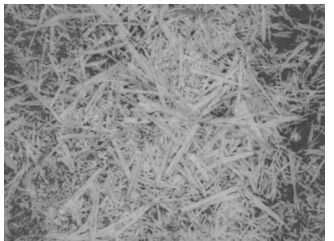

(a) $A_{d}=2.5 \mathrm{~mm}$

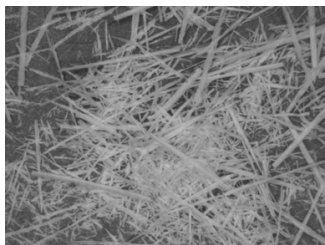

(b) $A_{d}=5 \mathrm{~mm}$

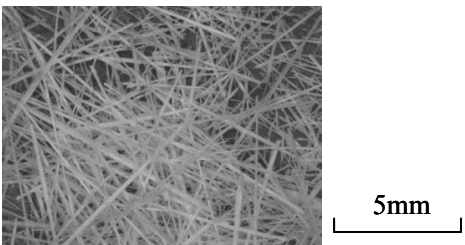

(c) $A_{d}=10 \mathrm{~mm}$

Figure 5: Microscopic images of fibers end-milled from bamboo $\left(f_{e n}=0.05 \mathrm{~mm} /\right.$ tooth, $\left.V=188 \mathrm{~m} / \mathrm{min}\right)$.

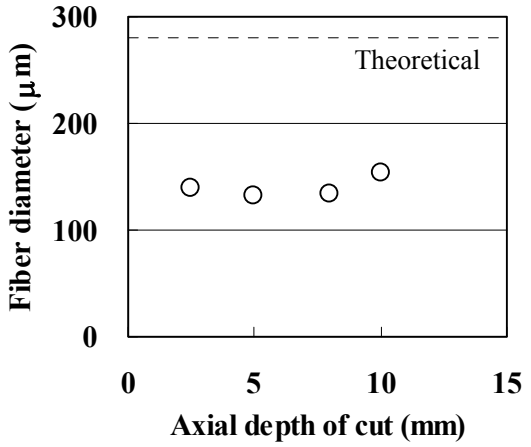

(a) Fiber diameter

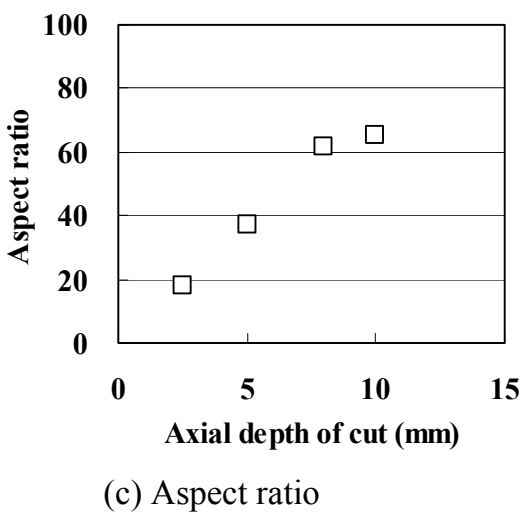

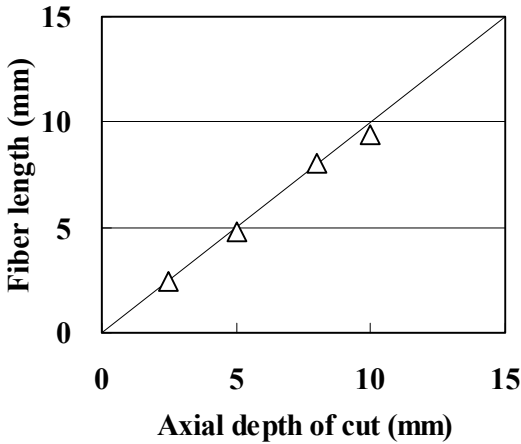

(b) Fiber length

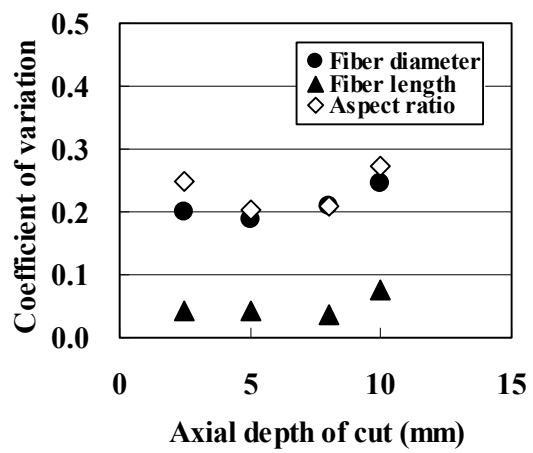

(d) Coefficient of variation

Figure 6: Change of bamboo fiber shape with depth of cut in fiber direction. $\left(f_{e n}=0.05 \mathrm{~mm} /\right.$ tooth, $\left.V=188 \mathrm{~m} / \mathrm{min}\right)$.

Figures 6 shows the changes in fiber shape with axial depth of cut under a constant feed of the end-mill center of $0.05 \mathrm{~mm} /$ tooth and a cutting speed of $188 \mathrm{~m} / \mathrm{min}$, the conditions determined to be optimum for acquiring high quality bamboo fibers efficiently as described in section 3.1. Moreover, $L$ and $h$ are 
respectively $548.5 \mu \mathrm{m}$ and $9.1 \mu \mathrm{m}$, respectively, under the same condition of constant fiber section for various cutting conditions as given in section 3.1.

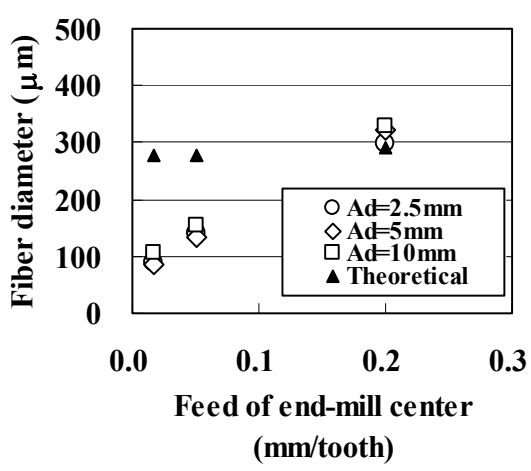

(a) Fiber diameter

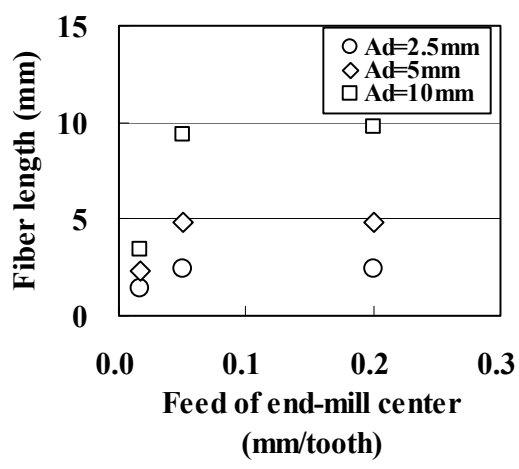

(b) Fiber length

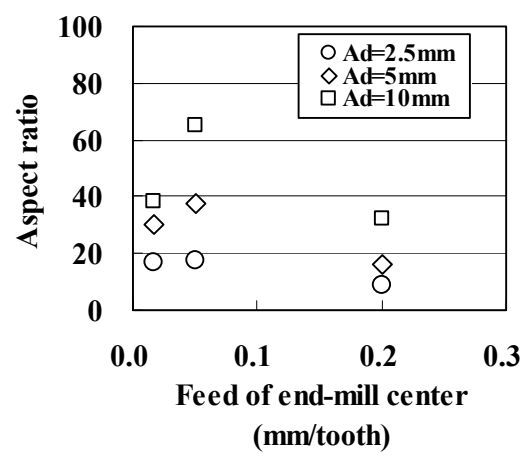

(c) Aspect ratio

Figure 7: Change of bamboo fiber shape with feed of the end-mill center and the depth of cut in fiber direction $\left(f_{e n}=0.05 \mathrm{~mm} / \mathrm{tooth}\right.$, $V=188 \mathrm{~m} / \mathrm{min}$ ).

It is clear that the fiber diameter measured shows almost constant value, which is almost half of theoretical one, with the axial depth of cut as shown in Fig. 6(a). On the other hand, the fiber length increases with the axial depth of cut as shown in Fig. 6(b). The result shows that the fiber length agrees very well with the axial depth of cut, as the data points lie almost exactly on a line of slope 1 (Fig.6(b)). As a result, aspect ratio increases with axial depth of cut as shown in Fig. 6(c). Fibers with a large aspect ratio are desirable to confer superior material properties to the FRP. It may be effective to increase the axial depth of cut in order to obtain high quality bamboo fibers. However, the coefficient of variation of fiber diameter, length and aspect ratio seem to have minimum values at an axial cut depth from 5 to $8 \mathrm{~mm}$. Therefore, it seems effective to set the axial cut depth from 5 to $8 \mathrm{~mm}$ in order to acquire high quality bamboo fibers. 


\subsection{Influence of feed of end-mill center on acquired bamboo fiber quality}

In this section, we investigate the change in shape of the fiber section with changes in the feed of the end-mill center adjusting spindle speed and the feed speed based on eqn (11). In this study, cutting arc length $L$ is constant because $L$ is a function of the end-mill radius and the depth of cut in the radius direction per one cycle as described by eqn (8). However, end-mill radius is a constant $3 \mathrm{~mm}$ and the depth of cut in the radius direction per one cycle is a constant $0.05 \mathrm{~mm}$. On the other hand, the maximum thickness of $h$ changes with spindle speed and feed speed under a constant end-mill radius, depth of cut in the radius direction per one cycle, and number of the cutting edge of the end-mill as shown in eqn (9). Therefore, the shape of bamboo fibers end-milled under various values for the feed of the end-mill center, determined by dividing the feed of the end-mill center by the spindle speed, and the axial cut depth in the bamboo fiber direction are investigated in this section. Larger values for the feed of the end-mill center give thinner end-milled bamboo fibers. The maximum thickness of $h$ is 3.0, 9.1, and $36.4 \mu \mathrm{m}$ for values of the feed of the end-mill center of $0.02,0.05$, and 0.20 $\mathrm{mm} / \mathrm{tooth}$, that is, the theoretical fiber diameter is 276,279 , and $292 \mu \mathrm{m}$, respectively, in this study.

Figure 7 shows the experimental results. It is clear that the smaller diameter bamboo fibers can be obtained with smaller values of the feed of the end-mill center, independent of the axial depth of cut in the fiber direction as shown in Fig. 7(a). In the case of a feed of the end-mill center of $0.20 \mathrm{~mm} / \mathrm{min}$, the fiber diameter measured agrees with theoretical one of $292 \mu \mathrm{m}$. However, the fiber diameter becomes smaller in case of smaller feed of the end-mill center of 0.05 $\mathrm{mm} /$ tooth. On the other hand, the fiber length is controlled very well by the axial depth of cut at a feed of the end-mill center of $0.05 \mathrm{~mm} /$ tooth or greater. However, the fiber length becomes smaller in the case of a small feed of the endmill center of $0.02 \mathrm{~mm} /$ tooth for each axial depth of cut. As a result, the aspect ratio attains a maximum at a feed of the end-mill center of $0.05 \mathrm{~mm} /$ tooth when $h$ is $9.1 \mu \mathrm{m}$. Therefore, a feed of the end-mill center of $0.05 \mathrm{~mm} /$ tooth seems suitable for obtaining superior bamboo fibers in end-milling of bamboo pipe.

\section{Conclusions}

End-milling using a machining center that follows a spiral tool path was tried for the production of high quality bamboo fibers. The shape of the fibers end-milled from bamboo pipe was evaluated under various cutting conditions, giving the following results.

(1) End-milling with a machining center that follows a spiral tool path is effective for obtaining high quality, straight bamboo fibers with no thermal damage.

(2) It is possible to accurately control the bamboo fiber length by adjusting the axial depth of cut.

(3) A higher cutting speed can provide bamboo fibers with smaller diameter. However, the decrease in bamboo fibers diameter with higher cutting speed saturates at a certain cutting speed. 
(4) Suitable conditions were determined for acquiring bamboo fibers of the desired shape.

\section{Acknowledgement}

This research is supported by the Research and Development Center for Engineering Application of Bamboo Resources at Doshisha University.

\section{References}

[1] Ogawa K., Hirogaki T., Aoyama E. and Katayama T., Data mining of optimum condition to acquire bamboo micro-fiber with mechanical method, High Performance Structures and Materials II, WIT PRESS, pp.441-450, 2004.

[2] Jana S. C. and Prieto A., On the development of natural fiber composites of high-temperature thermoplastic polymers, Journal of Applied Polymer Science, Vol. 9, No. 28, pp.2159-2167, 2002.

[3] Li H. and Sain M. M., High stiffness natural fiber-reinforced polypropylene composites, Polymer-Plastics Technology and Engineering, Vol.42, No.5, pp.853-862, 2003.

[4] Luo S. and Netravani A. N., Interfacial and mechanical properties of environment-friendly 'green' composites made from pineapples fibers and poly (hydroxybutyrate-co-valerate) resin, Journal of Materials Science, Vol. 34, No. 15, pp.3709-3719, 1999.

[5] Ogawa K., Hirogaki T., Aoyama E., Tomioka Y., and Shiomi T., Shape Control of Fibers End-milled from Bamboo with a Machining Center, Proc. of The $3^{\text {rd }}$ International Conference on Leading Edge Manufacturing in 21st Century, pp.565-570, 2005.

[6] Thwe M. M. and Liao K., Environmental effects on bambooglass/polypropylene hybrid composites, Journal of Materials Science, Vol. 38, No. 2, pp.363-376, 2003.

[7] Martikka H. and Katajisto J., Study of Natural Fiber Reinforced Biodegradable Composite Materials for Designing Optimally Sustainable Products, Proc. of the $23^{\text {rd }}$ Riso International Symposium on Materials Science, pp. 251-258, 2002.

[8] Takagi H. and Ichihara Y., Effect of fiber length on mechanical properties of "green" composites using a starch-based resin and short bamboo fibers, JSME International Journal, Series A: Solid Mechanics and Material Engineering, Vol. 47, No. 4, pp.551-555, 2004.

[9] A. Varada RaJulu, S. Allah Baksh, G. Ramachandra Reddy and K. Narasimha Chary, Chemical Resistance and Tensile Properties of Short Bamboo Fiber Reinforced Epoxy Composites, Journal of Reinforced Plastics and Composites, Vol. 17, No. 17, pp. 1507-1511, 1998.

[10] Seema Jain, U. C. Jindal and Rakesh Kumar, Development and fracture mechanism of the bamboo/polyester resin composite, Journal of Materials Science Letters, 12, pp. 558-560, 1993. 